\title{
ANTIOXIDANT ACTIVITY OF THE TOPICAL PREPARATION OF BULUNG SANGU (Gracilaria spp) EXTRACT
}

\author{
Maria Malida Vernandes Sasadara, I Gede Putu Wirawan*, Made Sritamin, \\ I Ketut Suada, and Wayan Adiartayasa \\ Faculty of Agriculture, Udayana University \\ *Corresponding author: igpwirawan@unud.ac.id
}

\begin{abstract}
Bulung Sangu (Gracilaria spp) as many other macroalgae, is a source of beneficial phytochemical for health. Phytochemicals in macroalgae are widely used as active ingredients in cosmetic preparations. The study was aimed to determine the antioxidant properties of Bulung Sangu formulated in topical preparation. Bulung Sangu was macerated in ethanol 96\% following by extract formulation in cream preparation in two concentrations: $5 \%$ and 10\%. Antioxidant activity was determined against DPPH radical, compared to ascorbic acid. Percentage of reducing power in five concentration series $(10,20,30,40$, and $50 \mu \mathrm{m} / \mathrm{ml}$ ) statistical analyzes using one-way ANOVA with $95 \%$ of confidence level, following by $\mathrm{IC}_{50}$ measurement. Absorbance was read in wavelength of $517 \mathrm{~nm}$. Concentration of $5 \%$ and $10 \%$ cream extract exhibited $\mathrm{IC}_{50}$ of $13,091 \mu \mathrm{g} / \mathrm{ml}$ and $11,867 \mu \mathrm{g} / \mathrm{ml}$, respectively. These values are lower than $\mathrm{IC}_{50}$ of ascorbic acid $(18,505 \mu \mathrm{g} / \mathrm{ml})$, indicating the strong antioxidant properties of Bulung Sangu extract cream which is more potential than ascorbic acid. Bulung Sangu exhibit a potential source for being developed as medicine and cosmetics in topical preparation.
\end{abstract}

Keywords: seaweed, extraction, antioxidant phytochemical, DPPH, cosmetics

\section{INTRODUCTION}

Nowadays, the consumption of herbal medication and natural products has been become a developing trend. Formulation of plant active compounds in various topical preparation intensively explore. Indonesia is a country with high diversity. Sundry plant and algae can be developed as the source of medicine and cosmetics. Bulung Sangu (Gracilaria spp) is one of seaweeds (macroalgae) widespread in Bali, usually consumed as vegetable. As many other macroalgae, Bulung Sangu is predicted as a source of beneficial phytochemical for health. Macroalgae is a source of important bioactive metabolites for drug development. Many of macroalgae compounds are used to treat diseases like cancer, inflammation, pain, arthritis, acquired immune-deficiency syndrome (AIDS), bacterial, fungal and viral infection (Almeida et al., 2011). Macroalgae contains organic compounds classified in polar phenols, phenol derivate such as phlorotannins and phloroglucinols and nonpolar phenols such as sterols, triterpenes 
tocopherols and pigments (Overland et al., 2019).

Julyasih et al. (2009) reported antioxidant activity from Bulung Sangu extract. The study also reported the presence of several types of carotenoids and chlorophyll pigments in Bulung Sangu extract which are knows for its antioxidant activity. This potential activity can be explored further by formulating Bulung Sangu as topical preparation aimed at skin protecting preparation.

One of the benefits of antioxidants for the skin is to inhibit the damaging process including premature aging. Premature aging is a damage that can be controlled by balancing the supply of antioxidants in the body. Aging is natural process leading to progressive organ damage marked by change in several clinical and histological condition. The main cause of aging is the imbalance of oxidant product and antioxidant leading to oxidative stress. Reactive oxygen species (ROS) is free radical generated from normal cellular metabolism. ROS can either harmful or beneficial for living system (Velika and Kron, 2012). ROS attack macromolecules and leading to cellular damage and homeostasis disorder. ROS targets every molecules in the living system, nonetheless the main targets are lipid, nucleic acid and protein (Lobo et al., 2010). Increase of ROS production can be influenced by several factors including sunlight exposure. UVA and UVB radiation cause an increase of NADPH oxidase activity leading to increase of ROS, followed by activation of epidermal keratinocyte and dermal fibroblast signaling pathway, thus activation of inflammatory genes (Fuller, 2019).

Prompted by these data we determined the antioxidant activity of Bulung Sangu formulated in topical preparation, against 2,2-diphenyl-1-picrylhydrazyl (DPPH) radical.

\section{MATERIALS AND METHODS}

Macroalgae material and preparation of the extract

Fresh bulung sangu was collected from Serangan Island, Bali. The sample was cleaned from impurities and washed with running water, then chopped to reduce the size. The chopped sample was then dried in oven at a temperature of $40^{\circ} \mathrm{C}$ for $3-7$ days until a constant weight was obtained. Extraction of the bioactive algal extract has been carried out as follows: the finely powdered algal material (750 g) was macerated by $96 \%$ ethanol $(1,5 \mathrm{~L})$ at room temperature for a period of three days with regular shaking. After filtration, organic solvent were evaporated under vacuum at $50^{\circ} \mathrm{C}$ to furnish dry ethanol extract. The crude extract were then stored at $-20^{\circ} \mathrm{C}$. 


\section{Cream formulation}

Bulung Sangu extract cream formulated in $\mathrm{o} / \mathrm{w}$ cream type. Cream formula divided into oil and water phase. Oil phase consisted of vaselin album 6,2\% ; mineral oil $13,8 \%$; isopropil miristat $1,5 \%$; stearic acid 7,5\% ; glycerol monostearate $5 \%$ and nipasol $0,05 \%$. Water phase consisted of triethanolamin $0,2 \%$; xanthan gum $0,2 \%$; nipagin $0,01 \%$; Bulung Sangu extract $5 \%$ or $10 \%$ (depends on cream concentration) and aquadest ad $100 \%$.

The oil phase was heated to $70^{\circ} \mathrm{C}$, while the water phase was heated to $60^{\circ} \mathrm{C}$. The water phase was added to the oil phase and stirred constantly counterclockwise. The extract was dissolved with aquadest at $35^{\circ} \mathrm{C}$ then added to the mixture of the oil phase and water phase. Aquadest was added to reach $100 \%$ of the formula weight.

\section{Preparation of Ascorbic Acid Standard}

$10 \mathrm{mg}$ of ascorbic acid were dissolved in $100 \mathrm{ml}$ methanol to obtain a solution with a concentration of $100 \mu \mathrm{g} / \mathrm{ml}$. Solution was then prepared into several final concentration of $10,20,30,40$, and $50 \mu \mathrm{g} / \mathrm{ml}$ for being used subsequently in antioxidant activity assay.

\section{Antioxidant activity based on the DPPH} assay

The antioxidant activity was measured using DPPH assay for two concentration of Bulung Sangu extract, 5\% (K5) and 10\% (K10). The DPPH solution was prepared in methanol and subsequently added to various concentrations of cream $(10,20,30,40$ and $50 \mu \mathrm{g} / \mathrm{ml}) .1,5 \mathrm{~mL}$ of test solution was added with $1 \mathrm{~mL}$ of DPPH solution, then incubated for 30 minutes. The absorbance of the solution was read with a UV-Vis spectrophotometer at a wavelength of $517 \mathrm{~nm}$. Methanol was used as the negative control. The percentage of antioxidant activity was calculated by this following formula:

Percentage of Reducing Power $(\%)=$ [(A control - A sample $) /$ A control $)]$ x 100

Control absorbance (A control) is absorbance of methanol in DPPH solution. Linear regressions were obtained for ascorbic acid, 5\% and 10\% Bulung Sangu extract cream, used to measure $\mathrm{IC}_{50}$ (Inhibitory Concentration)

\section{Statistical Analyses}

Data of percentage of reducing power was analyzed using One-Way ANOVA followed by Post Hoc Test Fisher's Least Significant Difference (LDS). Significant value were obtain by comparing the 
percentage of two creams in the same concentration. All statistical analyzes used $95 \%$ of confidence level.

\section{RESULTS AND DISCUSSION}

Medicinal plant provides the source of beneficial phytochemical playing a role in medicine development. Most phytochemical are phenolic and flavonoid compounds reported for having various beneficial effect for health including preventing cancer (Venugopal dan Liu, 2012). The use of natural sources in development and formulation of skin and cosmetics products leading to the intensive explorations of medicinal plants (Mukherjee et al., 2011). Seaweed (macroalgae) is known as functional food, rich of lipid mineral vitamins and bioactive substance such as polysaccharides, proteins and polyphenols (Namwar et al., 2013).

Antioxidant assay determined in vitro using DPPH method. This method is suitable to measure antioxidant capacity for organic solvent dissolved compounds especially ethanol (Kusumawati dan Indrayanto, 2013). DPPH is stable free radical in room temperature, act by reducing hydroxyl group of antioxidant to become a stable diamagnetic molecule. Percentage of DPPH scavenging activity depends on antioxidant concentrations (Onar et al., 2012).

The in vitro antioxidant activity of two extract concentrations were measured using DPPH assay. Percentage of reducing power showed in Table 1. Significant value showed the percentage of reducing power obtained from 5\% and 10\% Bulung Sangu extract consentration in the same test solution concentrations. Significant values $(\mathrm{p})<0,05$ stated significantly difference. Five solution concentrations showed different values of percentage of reducing power. Scavenging activity was increased in concentration dependent manner.

Linear regression obtained from five concentrations series from two different extract concentrations. 5\% and 10\% Bulung Sangu extract cream (K5) resulted in linear regression of $\mathrm{y}=0,1517 \mathrm{x}+47,982\left(\mathrm{R}^{2}\right.$ $0,9839)$ and $\mathrm{y}=0,1698 \mathrm{x}+47,985\left(\mathrm{R}^{2}\right.$ $0,8703)$, respectively. $\mathrm{IC}_{50}$ of $5 \%$ and $10 \%$ Bulung Sangu extract cream were $13,303 \mu \mathrm{g} / \mathrm{ml}$ and $11,867 \mu \mathrm{g} / \mathrm{ml}$, respectively (Tabel 2). $\mathrm{IC}_{50}$ define as the concentration needed for giving the scavenging of $50 \%$ of total free radical available. Lower value of $\mathrm{IC}_{50}$ indicating the higher scavenging activity (Molyneux, 2004). 
Table 1. Persentage of reducing power of 5\% and 10\% Bulung Sangu ethanol extract

\begin{tabular}{ccc}
\hline \multirow{2}{*}{ Concentrations $(\mu \mathrm{g} / \mathrm{mL})$} & \multicolumn{2}{c}{ Percentage of Reducing Power $(\%)$} \\
\cline { 2 - 3 } & $\mathrm{K} 5$ & $\mathrm{~K} 10$ \\
\hline 10 & $49,375 \pm 0,044$ & $48,564 \pm 0,092^{* *}$ \\
20 & $51,398 \pm 0,043$ & $51,732 \pm 0,076^{* *}$ \\
30 & $52,047 \pm 0,057$ & $54,557 \pm 0,109^{* *}$ \\
40 & $54,270 \pm 0,059$ & $55,416 \pm 0,360^{* *}$ \\
50 & $55,549 \pm 0,158$ & $55,473 \pm 0,016^{*}$ \\
\hline
\end{tabular}

Mean \pm SD

$* * \mathrm{p}<0,05$ compared to percentage of reducing power of $\mathrm{K} 5$ in the same concentration

Table 2. IC $_{50}$ value of DPPH radical scavenging activity

\begin{tabular}{lc}
\hline \multicolumn{1}{c}{ Sample } & IC50 $(\mu \mathrm{g} / \mathrm{ml})$ \\
\hline Bulung Sangu extract cream 5\% & 13,303 \\
Bulung Sangu extract cream 10\% & 11,867 \\
Ascorbic acid & 18,505 \\
\hline
\end{tabular}

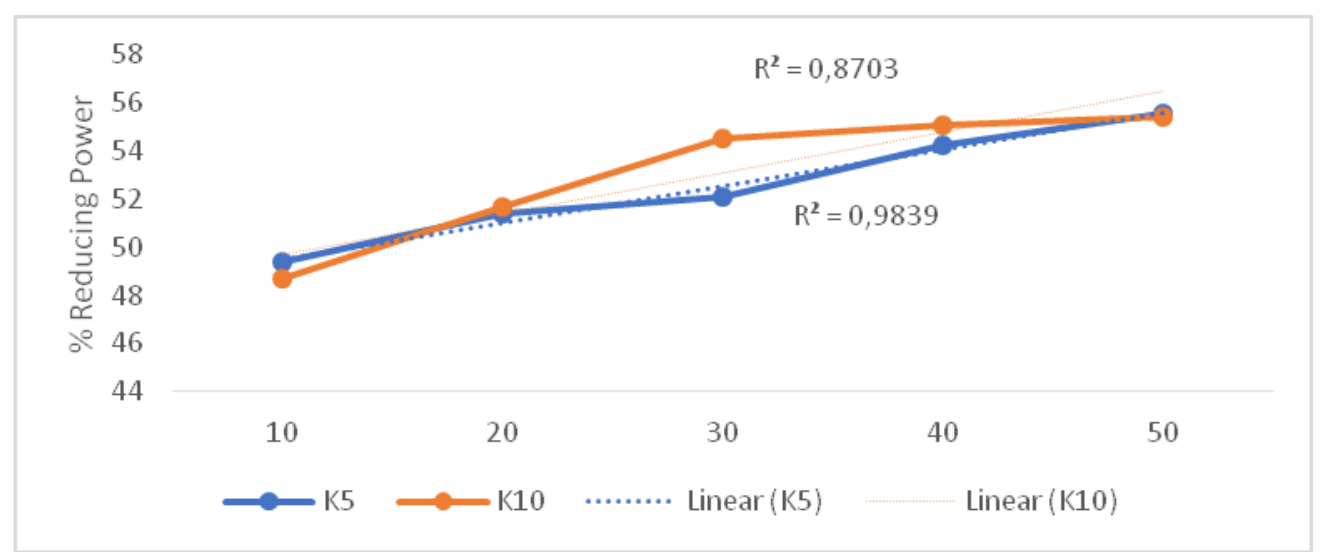

Fig. 1. Reducing power of different concentration of Bulung Sangu extract cream

$10 \%$ Bulung Sangu extract cream Compared to ascorbic acid, both 5\% and resulted in lower $\mathrm{IC}_{50}$ than 5\% Bulung Sangu $10 \%$ Bulung Sangu extract cream exhibit extract cream, but also with lower coefficient lower $\mathrm{IC}_{50}$. According to Phongpaichit correlation. 5\% Bulung Sangu extract cream (2007), $\mathrm{IC}_{50}$ of $10-50 \mu \mathrm{g} / \mathrm{ml}$ classified as showed higher coefficient correlation near to strong antioxidant compound. Compound 1 indicating that increase of reducing power with $\mathrm{IC}_{50}$ of $50-100 \mu \mathrm{g} / \mathrm{ml}$ classified as generated by $5 \%$ Bulung Sangu extract intermediate antioxidant activity while $\mathrm{IC}_{50}$ cream was higher than the other group. $>100 \mu \mathrm{g} / \mathrm{ml}$ classified as weak antioxidant. 
Prompted by the classification by Phongpaichit (2007), Bulung Sangu extract cream own strong antioxidant activity.

The antioxidant activities obtained from the extract in two different cream concentrations are higher that reported in Julyasih et al. (2009). Study by Julyasih et al. (2009) reported the antioxidant activity of Gracilaria spp ethanol extract was 9,6714\%. The difference may be due to the different process in extraction in which the maceration applied in the study was one hours with constant stirring by magnetic stirrer. In this study, the maceration applied was three days with frequent manual stirring. The longer maceration duration in this study may isolate more antioxidant compound thus resulted in higher antioxidant activity.

Antioxidant is molecule with ability to inhibit or stop radical reaction thus inhibit cellular damage (Nisme and Pal, 2015). Bulung Sangu extract reported for contain carotenoid and phenolic compounds (Julyasih, 2009). Polyphenols and carotenoids are two major phytochemical compounds playing role in antioxidant effect (Zhang et al., 2013). Carotenoids are responsible for pigmentations in animals, plants, and microorganism. In biological system, carotenoids gives antioxidant activity. The main structure of carotenoids is polyene backbone consisting of a series of conjugated $\mathrm{C}=\mathrm{C}$ bonds, which are able to interact with free radical and singlet oxygen and therefore act as antioxidant (Young and Lowe, 2018). Natural polyphenols are the most abundant antioxidant in human diets. Antioxidant properties of polyphenol are related to substitution of the hydroxyl groups in the aromatic rings of phenolics (Rokayya et al., 2013). Polyphenols classified in five classes: flavonoids, phenolic acids, stilbenes, tannins and coumarins. The total phenolic content and total antioxidant activity in phytochemical extract may have a direct relationship. Higher level of total phenolic contents usually resulted in higher antioxidant activity (Sun et al., 2002).

Antioxidant activity is important mechanism for skin protection. Especially to response premature skin aging (photoaging). The photoaging mechanism are predominantly the effect of UV radiation inducing ROS production. UV radiation also alters DNA or cellular homeostasis which together with ROS activate signal transduction pathway and inflammatory cascade. The photoprotective strategies should focused in several strategies including the blockade of UV photon incident, DNA repair, anti-inflammatory and immunomodulatory agents, or removal of ROS through antioxidant activity (Bosch et al., 2015).

UV radiation produces Reactive Oxygen Species (ROS) including hydroxyl 
free radicals, superoxide radicals, nitric oxide radicals and peroxyl radicals. Various chemical compounds are then converted to free radicals and initiating inflammation response. UV radiation exposure causes a rapid increase in NADPH oxidase triggering an increase in ROS, which then activates the keratinocyte signaling pathway in the epidermis and dermal fibroblasts, following by activation of inflammatory genes. ROS production is also mediate inflammatory response. ROS including hydroxyl free radicals, superoxide, nitric oxide and peroxyl radicals, subsequently turn other molecules into radicals and trigger chained radical reaction. UVB radiation causes the increase of NADPH oxidase furthermore increase in ROS production that will activate the signaling pathway in epidermal keratinocytes and dermal fibroblasts, following by activation of inflammatory genes (Fuller, 2019).

\section{CONCLUSION}

The present study demonstrated that Bulung Sangu extract cream exhibit strong antioxidant activity with $\mathrm{IC}_{50}$ values of $13,091 \mu \mathrm{g} / \mathrm{ml}$ and $12,429 \mu \mathrm{g} / \mathrm{ml}$, respectively. Compared to $\mathrm{IC}_{50}$ of ascorbic acid $(18,505 \mu \mathrm{g} / \mathrm{ml})$, Bulung Sangu extract cream exhibit lower $\mathrm{IC}_{50}$ indicating stronger antioxidant activity that ascorbic acid.

\section{ACKNOWLEDGEMENTS}

This study was supported by Udayana University Research Grant No. 8382/UN14.4.A/LT/2019.

\section{REFERENCES}

Almeida, C.L.F., Falcao, H.S., Lima, G.R., Montenegro, C., Lia, N.S., AthaydeFilho, P.F., Rodrigues, L.C., Souze, M.F., Barbosa-Filho, J.M., \& Batista, L.M. (2011). Bioactive from Marine Algae of the Genus Gracilaria. Int. J. Mol. Sci. 12, 4550 - 4573. http://doi.org/10.3390/ijms12074550

Bosch, R., Philip, N., Suarez-Perez, J., Juarranz, A., Devmurari, A., Chalensouk-Khaosaat, J., \& Gonzales, S. (2015). Mechanisms of Photoaging and Cutaneous Photocarcinogenesis, and Photoprotective Strategies with Phytochemicals. Antioxidant. 4,248268. http://doi.org/ 10.3390/antiox 4020248

Fuller, B. (2019). Role of PGE-2 and Other Inflammatory Mediators in Skin Aging and Their Inhibition by Topical Natural Anti-Inflammatories. Cosmetics. 6(6),1-28. http://doi.org/ 10.3390/cosmetics6010006

Julyasih, S.R., Wirawan, I.G.P., Harijani, W.S., \& Widajati, W. (2009). Aktivitas Antioksidan Beberapa Jenis Rumput Laut (Seaweeds) Komersial di Bali. Paper presented at Proceedings of Seminar Nasional Akselerasi pengembangan Teknologi Pertanian Dalam Mendukung Revitalisasi Pertanian, Jawa Timur, ID: Universitas Pembangunan Nasional "Veteran" Jawa Timur.

Kusumawati, I., \& Indrayanto, G. (2013). Natural Antioxidant in Cosmetics. In Atta-Ur-Rahman (Editor)., Studies in Natural Products Chemistry (pp. 486 - 505). Amsterdam, Elsevier 
Lobo, V., Patil, A., Phatak, A., \& Chandra, N. (2010). Free radicals, antioxidants and functional foods: Impact on human health. Phcog Rev. 4(8):118126. https://doi.org/10.4103/09737847.70902

Molyneux, P. (2004). The use of the stable free radical diphenylpicrylhydrazyl (DPPH) for estimating antioxidant activity. Songklanakarin J. Sci. Technol. 26(2):211-219.

Mukherjee, P.K., Maity, N., Nema, N.K., \& Sarkar, B.K. (2011). Bioactive compounds from natural resources against skin aging. Phytomedicine. 19:

64-73. https://doi.org/10.1016/j.phymed.201 1.10 .003

Namwar, F. Mohamad, R. Baharara, J. ZafarBalanejad, S. Fargahi, F., \& Rahman, H.S. (2013). Antioxidant, Antiproliferative, and Antiangiogenesis Effects of Polyphenol-Rich Seaweed (Sargassum muticum). BioMed Research International. http://dx.doi.org/10.1155/2013/60478 7

Nimse, S.B., Pal, D. 2015. Free radicals, natural antioxidants, and their reaction mechanisms. Royal Society of Chemistry. 5:27986-28006. http://doi.org/10.1039/C4RA13315C

Onar, H.C., Yusufoglu, A., Turker, G., \& Yanardag, R. (2012). Elastase, tyrosinase and lipoxygenase inhibition and antioxidant activity of an aqueous extract from Epilobium angustifolium L. leaves. J. Med. Plants Res. 6(5):716-726. http://doi.org/10.5897/JMPR11.1127

Overland, M., Mydland, L.V., \& Skrede, A. (2019). Marine macroalgae as sources of protein and bioactive compounds in feed formonogastric animals. Journal of the Science of Food and Agriculture. 99:13-24.
Phongpaichit,S., Nikom, J., Rungjindamai, N., Sakayaroj, J., HutadilokTowatana, N., Rukachaisirikul, V., Kirtikara, K. (2007). Biological activities of extracts from endophytic fungi isolated from Garcinia plants. FEMS Immunol. Med. Microbiol. 51 517-525. https://doi.org/10.1111/j.1574695X.2007.00331.x

Rokayya, S., Li, C.J., Zhao, Y., Li, Y., \& Sun, C.H. (2013) Cabbage (Brassica oleracea L. var. capitata) phytochemicals with antioxidant and anti-inflammatory potential. Asian Pac. J. Cancer Prev. 14 : 6657-6662. https://doi.org/10.7314/APJCP.2013.1 4.11.6657

Sun, J., Chu, Y.F., Wu, X.Z., \& Liu, R.H. (2002) Antioxidant and antiproliferative activities of common fruits. J. Agric. Food Chem. 50 : 7449-7454. https://doi.org/10.1021/jf0207530

Velika, B.C., \& Kron, I. (2012). Antioxidant properties of benzoic acid derivatives against Superoxide radical. Free Rad. Antiox. 2(4),62-67. http://doi.org/ 10.5530/ax.2012.4.11

Venugopal, R., \& Liu, R.H. (2012). Phytochemicals in diets for breast cancer prevention: The importance of resveratrol and ursolic acid. Food Sci Hum Wellness. 1: 1-13. https://doi.org/10.1016/j.fshw.2012.1 2.001

Young, A.J. \&Lowe, G.L. (2018). Carotenoids-Antioxidant Properties. Antioxidants. $7: 28$. https://dx.doi.org/10.3390\%2Fantiox7 020028

Zhang, Y.J., Deng, G.F., Xu, X.R., Wu, S., Li, S., \& Li, H.B. (2013) Chemical components and bioactivities of cape gooseberry (Physalis peruviana). Int. J. Food Nutr. Saf. 3:15-24. 